\title{
Primary Completion Date
}

National Cancer Institute

\section{Source}

National Cancer Institute. Primary Completion Date. NCI Thesaurus. Code C142643.

The date on which the last clinical study subject was given the final intervention or examination in order to obtain information to support the primary outcome. 